\title{
The Multicomponent, Multitarget Therapy SUC in Cats with Chronic Kidney Disease: A Multicenter, Prospective, Observational, Nonrandomized Cohort Study
}

\author{
Uta Brandenburg $^{\mathrm{a}}$ Gabriele Braun $^{\mathrm{b}}$ Peter Klein ${ }^{c}$ Erich Reinhart ${ }^{\mathrm{d}}$ \\ ${ }^{a}$ Tierärztliches Institut Göttingen, Göttingen, Germany; ${ }^{\text {b }}$ Klifovet AG, Munich, Germany; ${ }^{c}$ d.s.h. statistical services \\ $\mathrm{GmbH}$, Rohrbach, Germany; ${ }^{\mathrm{d} B i o l o g i s c h e ~ H e i l m i t t e l ~ H e e l ~ G m b H, ~ B a d e n-B a d e n, ~ G e r m a n y ~}$
}

\section{Keywords}

Katze $\cdot$ Chronische Niereninsuffizienz · Solidago compositum ad us. vet. • Ubichinon compositum . Coenzyme compositum

\begin{abstract}
Background: We compared the natural multicomponent, multitarget therapy SUC (Solidago compositum ad us. vet., Ubichinon compositum and Coenzyme compositum, Heel $\mathrm{GmbH}$, Baden-Baden, Germany) to the well-known angiotensin-converting enzyme inhibitor benazepril in a prospective, observational, nonrandomized, two-arm cohort study of cats with chronic kidney disease (CKD). The objective was to assess the tolerability and the effectiveness of SUC in cats with CKD. Material and Methods: One hundred thirty-six cats were screened for CKD, and 70 cats were eligible for the study. Thirty-three cats were assigned to the SUC treatment, and 35 cats received benazepril. All cats were diagnosed with CKD. The follow-up period was 168 days. Response was assessed as an improved or stable serum creatinine from baseline to the end of the study. Additionally, a clinical summary score, as measure of quality of life, was evaluated. Results: Serum creatinine remained close to baseline in both study groups with slightly improved values in the SUC group. The clinical summary score improved significantly in the SUC group on days 3, 7, 28, 56 and 112 , but not on day 168 . Conclusions: Within the limitations of the study, the results carry implications for the useful-
\end{abstract}

karger@karger.com

www.karger.com/cmr

Karger ${ }^{\prime \prime}=$ (c) 2020 The Author(s)
Published by S. Karger AG, Basel
Open acce

This article is licensed under the Creative Commons AttributionNonCommercial-NoDerivatives 4.0 International License (CC BYNC-ND) (http:/ /www.karger.com/Services/OpenAccessLicense). NC-ND) (http.//www.karger.com/Services/OpenAccessLicense). Usage and distribution for commercial purposes as well as any dis ness of SUC as an interesting new treatment option for feline CKD. The results indicate that SUC might be more effective if given at least twice weekly.

(C) 2020 The Author(s) Published by S. Karger AG, Basel

\section{Schlüsselwörter}

Katze $\cdot$ Chronische Niereninsuffizienz · Solidago compositum ad us. vet. - Ubichinon compositum . Coenzyme compositum

\section{Zusammenfassung}

Hintergrund: Es wurde die Multicomponent-MultitargetTherapie SUC (Solidago compositum ad us. vet., Ubichinon compositum und Coenzym compositum, Heel GmbH, Baden-Baden, Deutschland) mit dem bekannten Angiotensin-Converting-Enzym-Inhibitor (ACEI) Benazepril in einer prospektiven, nichtrandomisierten, zweiarmigen Kohortenstudie an Katzen mit chronischer Nierenerkrankung (CNE) untersucht. Ziel war es, die Verträglichkeit und Wirksamkeit von SUC bei Katzen mit CNE zu beur- 
teilen. Material und Methoden: Einhundertsechsund dreißig Katzen mit Verdacht auf CNE wurden untersucht, bei 70 Katzen wurde eine CNE diagnostiziert und diese wurden in die Studie aufgenommen. Dreiunddreißig Katzen wurden mit SUC therapiert und 35 Katzen erhielten Benazepril. Der Beobachtungszeitraum betrug 168 Tage. Das Ansprechen auf die Therapie wurde definiert als ein verbessertes bzw. ein stabiles Serumkreatinin am Ende der Studie im Vergleich zum Ausgangswert. Zusätzlich wurde zur Bewertung der Lebensqualität der Katzen ein klinischer Summenscore erfasst. Ergebnisse: Das Kreatinin blieb in beiden Studiengruppen nahezu unverändert, mit geringgradig niedrigeren Werten in der SUC-Gruppe. Der klinische Summenscore verbesserte sich in der SUCGruppe im Vergleich zur Benazepril-Gruppe signifikant an den Tagen 3, 28, 56 und 112, nicht aber am Tag 168. Schlussfolgerungen: Die Ergebnisse zeigen, dass SUC eine neuartige und gut verträgliche Behandlungsalternative zu ACEls bei Katzen mit leichter bis mittelschwerer CNE darstellt. Die Ergebnisse deuten darauf hin, dass eine zweimal wöchentliche Therapie mit SUC effektiver sein könnte als eine Dosierung einmal pro Woche.

(c) 2020 The Author(s)

Published by S. Karger AG, Basel

\section{Background}

Chronic kidney disease (CKD) in cats is defined as a loss of kidney function [1]. CKD has been diagnosed with increasing numbers in recent decades $[2,3]$, and risk factors associated with the development of CKD have been identified [4]. Especially in cats, renal disorders are the number one cause for mortality in cats $\geq 5$ years of age [5-8].

Symptoms of CKD are dependent on the severity of the disease. Common signs of CKD are lethargy, reduced appetite and consequently weight loss presuming a reduced quality of life [9]. In addition, polyuria/polydipsia, elevated creatinine concentrations, dehydration, proteinuria and lower urinary specific gravity (USG) are common [10].

The diagnostic workup should include complete blood count, serum chemistry, blood pressure and urine analysis with urine protein-to-creatinine ratio (UP/C) [10, 11]. A staging system for cats with CKD has been established by the International Renal Interest Society (IRIS) [12] (Table 1). The strongest predictors for survival are serum creatinine and UP/C [13].

CKD is an irreversible and progressive disease $[14,15]$, and the treatment aims to preserve kidney function and to maintain a good quality of life [10]. Treatment recommendations for feline CKD include dietary adjustments with protein and phosphate restriction, and management of potassium balance and anemia, as appropriate [16-20].
In addition, pharmacotherapy is often prescribed when proteinuria is present. For renal proteinuria angiotensinconverting enzyme inhibitors (ACEIs) are part of the standard of care in both cats and dogs [19, 21-24].

The combined treatment with Solidago compositum ad us. vet. (Heel GmbH, Baden-Baden, Germany), Ubichinon compositum (Heel GmbH, Baden-Baden, Germany) and Coenzyme compositum (Heel $\mathrm{GmbH}$, Baden-Baden, Germany) with numerous ingredients (online suppl. Table 1, for all online suppl. material, see www.karger.com/doi/10.1159/000506698) has been developed as an integrative treatment for cats with CKD following a multicomponent, multitarget principle. In the following, the abbreviation SUC (Solidago ad us. vet., Ubichinon compositum and Coenzyme compositum) is being used. In most cats diagnosed with CKD, chronic tubulointerstitial nephritis and renal fibrosis are common findings on histology [25-27]. In humans, tubulointerstitial nephritis and renal fibrosis have been linked to cell senescence in kidney tissue [28, 29]. Senescent cells show expression of proinflammatory cytoand chemokines causing inflammation, fibrosis and loss of function of organs [28]. Preventing the transition from normal to senescent cells has been linked to Solidago virgaurea, the main ingredient of Solidago compositum ad us. vet. [30]. Furthermore, compounds isolated from $S$. virgaurea are reported to have antimicrobial, analgesic, anti-inflammatory, spasmolytic and mild diuretic activity [31]. The diuretic activity of S. virgaurea has been linked to the inhibition of ACE comparable to the effect of benazepril [31]. ACE plays a pivotal role in the development of CKD causing glomerular hypertension resulting in glomerular damage and activation of proinflammatory and profibrotic pathways [32]. To summarize, $S$. virgaurea can reduce the inflammation of kidney tissue and protect organ function by preventing fibrosis. Ubichinon compositum and Coenzyme compositum can enhance mitochondrial respiration leading to reduced oxidative stress in the target tissue caused by an impaired mitochondrial respiratory system $[33,34]$. There is a growing body of evidence that reduced respiratory capacity of mitochondria might be the cause or the consequence of chronic kidney disorders in patients [35-37].

Despite a lot of experience with the use of SUC, only a small number of studies are available showing effectiveness and tolerability of SUC in the cat [38-40]. The primary aim of this multicenter, prospective, two-armed, observational nonrandomized cohort study was to assess tolerability. The second aim was to show effectiveness of the treatment. In this clinical study, SUC was compared to the ACEI benazepril in cats with CKD. Additionally, quality of life was assessed by the owner and the treating veterinarian. 


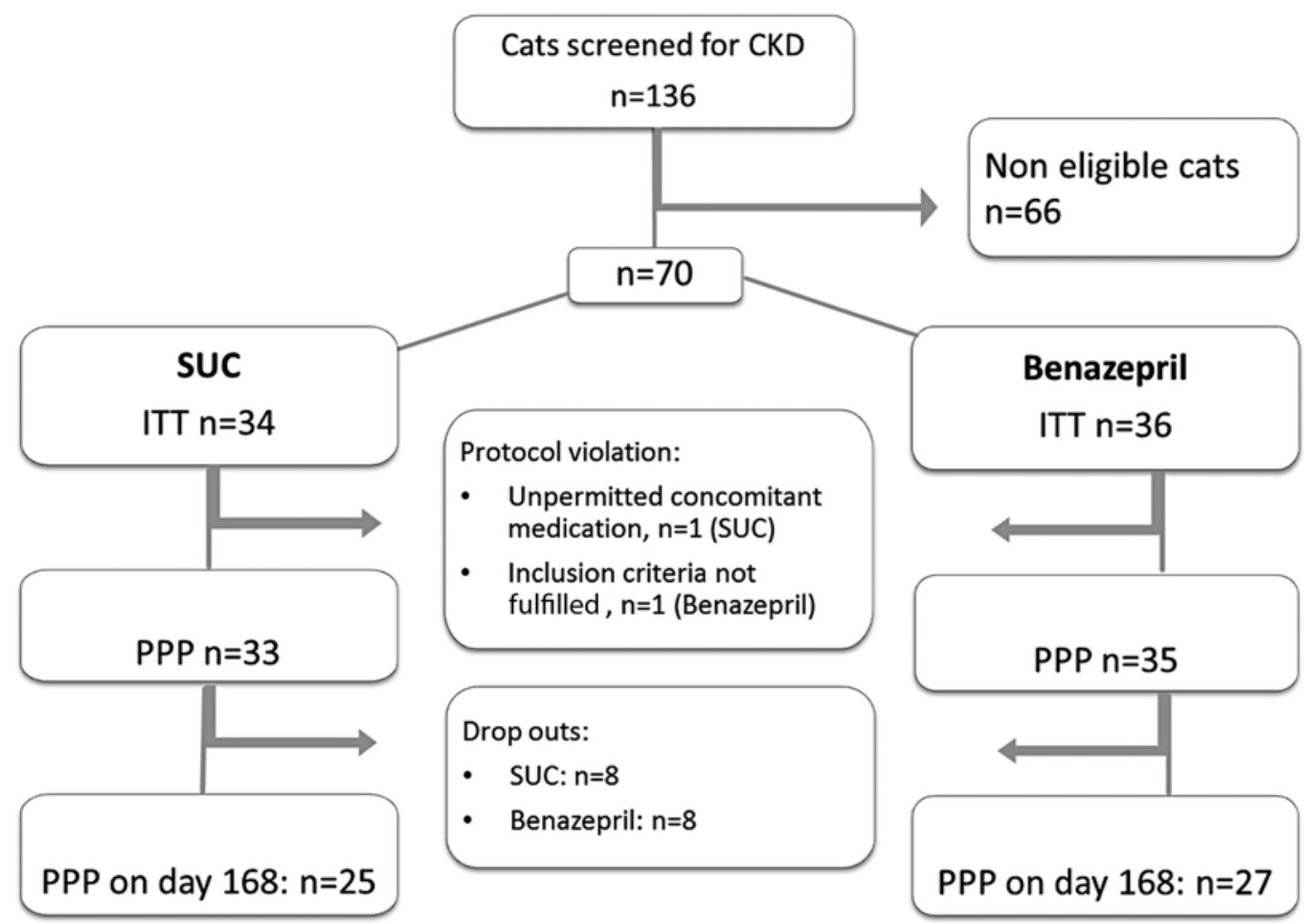

ITT = intention to treat $\mathrm{PPP}=$ per protocol population

Fig. 1. Flowchart of the study.

\section{Material and Methods}

\section{Cats}

A total of 136 client-owned cats $>12$ months suspected or known to have CKD were screened at 12 veterinary centers in Germany from 2012 to 2016 . Seventy cats were eligible for the study (Fig. 1).

\section{Inclusion Criteria}

Cats of either sex were eligible for inclusion if owner informed consent was given. Cats with a body weight of $2.0-10 \mathrm{~kg}$ were included in the study. All cats had to be diagnosed with clinically stable CKD based on the criteria of the IRIS society. The IRIS stage includes serum creatinine, UP/C and blood pressure measurements (Table 1). The diagnosis of CKD was based on clinical history, physical examination and laboratory findings. The following criteria had to be met: serum creatinine concentration $\geq 2$ and $\leq 5$ $\mathrm{mg} / \mathrm{dL}$ and USG $\leq 1.035$. Cats with a clinical summary score of $10-15$ were eligible for the study. Cats receiving a renal diet were eligible if they had received the diet for at least 4 weeks before enrollment in the study; also cats with diabetes mellitus or hyperthyroidism were eligible if the concomitant disease had been stable for at least 4 weeks.

\section{Exclusion Criteria}

Cats were not eligible for the study if they had a serum creatinine $<2$ and $>5 \mathrm{mg} / \mathrm{dL}$, a clinical summary score below 10 or above 15 , bacterial urinary tract infection or received concomitant treatment within 14 days before enrollment with other ACEIs, diuret-
Table 1. IRIS stage from the International Renal Interest Society (IRIS)

\begin{tabular}{|c|c|c|}
\hline IRIS stage & $\begin{array}{l}\text { Creatinine, } \\
\mathrm{mg} / \mathrm{dL}\end{array}$ & Comment \\
\hline At risk & $<1.6$ & Predisposing parameters \\
\hline 1 & $<1.6$ & $\begin{array}{l}\text { Nonazotemic, some other } \\
\text { renal abnormalities present }\end{array}$ \\
\hline 2 & $1.6-2.8$ & Mild renal azotemia \\
\hline 3 & $2.9-5.0$ & Moderate renal azotemia \\
\hline 4 & $>5.0$ & $\begin{array}{l}\text { Risk of systemic clinical } \\
\text { signs and uremic crisis }\end{array}$ \\
\hline IRIS substage & $\mathrm{UP} / \mathrm{C}$ value & Comment \\
\hline 1 & $<0.2$ & Nonproteinuric \\
\hline 2 & $0.2-0.4$ & Borderline proteinuric \\
\hline 3 & $>0.4$ & Proteinuric \\
\hline IRIS substage & $\begin{array}{l}\text { Systolic blood } \\
\text { pressure, } \\
\text { mm Hg }\end{array}$ & Comment \\
\hline 1 & $<140$ & Normotensive \\
\hline 2 & $140-159$ & Prehypertensive \\
\hline 3 & $160-179$ & Hypertensive \\
\hline 4 & $\geq 180$ & Severely hypertensive \\
\hline
\end{tabular}




\begin{tabular}{|l|l|l|l|}
\hline Day 1-6 & Day 7-14 & Day 15-55 & Day 56-168 \\
\hline Daily dosing & Dosing every other day & Dosing twice weekly & Dosing once weekly \\
& & \\
\hline
\end{tabular}

Fig. 2. Dosing scheme of SUC during the study.

ics, nonsteroidal anti-inflammatory drugs, corticoids, nephrotoxic antibiotics, antiemetics or appetite stimulants. Cats treated with homeopathic or herbal remedies 28 days prior to study enrollment and for the duration of the study were excluded.

\section{Study Design}

This was a multicenter, prospective, observational, two-armed, nonrandomized, open-label cohort study conducted in 12 German veterinary practices between July 2012 and June 2016. The design and conduct of the study were in accordance with the Guidelines for Good Clinical Practice (GCP) VICH GL9 [41]. A contract research organization (Klifovet AG, Munich, Germany) was requested to design the study protocol. Suitable study sites were selected from a pool of investigators experienced in the conduct of GCP compliant clinical studies and in monitoring the active study phase according to GCP. The study sites were responsible for the data management and the reporting of the study results to Klifovet AG. Study sites were regarded suitable if they had experience in the use of the study medication, had enough patients to recruit the required number of cases and were equipped to collect the clinical data, for example cystocentesis.

\section{Treatments}

Cats were treated with either SUC or benazepril (Benefortin ${ }^{\circledR}$ Flavour $2.5 \mathrm{mg}$ tablets; Boehringer Ingelheim Vetmedica $\mathrm{GmbH}$, Ingelheim, Germany). Each participating center treated all cats with either SUC or benazepril. To ensure the correct treatment with either SUC or benazepril, the study sites that were familiar with benazepril treated all cats with benazepril and the study sites familiar with SUC used solely SUC. This design assured that veterinarians could not compare treatment results between groups to reduce the bias caused by the unblinded design of this observational study.

SUC is composed of numerous ingredients displayed in online supplementary Table 1 . All components of SUC have dilutions in the range of $10^{4}-10^{10}$. The components were mixed in equal parts, and a $3-\mathrm{mL}$ solution was administered subcutaneously by the veterinarian at the first visit, followed by oral administration by the owner. Treatment was administered daily for the first week, every second day in the second week, twice weekly from day 21 to day 55 , and then the dose was reduced to once weekly (Fig. 2). Benazepril was given at $0.5-1.0 \mathrm{mg} / \mathrm{kg}$ p.o. every $24 \mathrm{~h}$ as a $2.5-\mathrm{mg}$ tablet according to the product label (cats with a body weight of $2.5-5 \mathrm{~kg}$ received 1 tablet, and cats with a body weight of $>5 \mathrm{~kg}$ received 2 tablets). There was no standardization of cat diets and a renal diet was allowed if started $\geq 4$ weeks prior to enrollment. Correction of dehydration by infusion was allowed within the study period, but infusion had to be discontinued at least $48 \mathrm{~h}$ before blood and urine sampling.

\section{Study Duration and Evaluation}

Cats were observed for 168 days. Clinical examinations were performed at the screening visit, at baseline (day 0 ) and on days 3 , $7,28,56,112$ and 168 , respectively, within a time window of \pm 1 day until day 7 and \pm 3 days afterwards. Blood pressure was measured noninvasively at the screening visit, and on days 56 and 168 if possible. At each time point, 5 measurements were taken, and a mean blood pressure was calculated. Urine was collected at screening and on days 7, 28, 56, 112 and 168 to determine UP/C and USG. Cystocentesis was the preferred method at all time points. Additionally, complete blood count and blood chemistry were done at the screening visit and on days 7, 28, 56, 112 and 168. Response was assessed as a decreased or stable serum creatinine compared to baseline. Clinical parameters were recorded at each visit.

\section{Clinical Summary Score}

Quality of life was assessed at each visit using a clinical summary score according to Mizutani et al. [22] on a scale from 1 to 4 for each variable. The clinical summary score included 5 variables such as general behavior, appetite, vomiting, dehydration and fur condition. The sum of all values from the 5 variables was calculated and displayed as clinical summary score, with 5 being the lowest value and 20 the highest. A high value is indicative of a markedly reduced quality of life. General behavior was graded as: 1 = normal activity, 2 = slight asthenia (slight weakness), 3 = moderate asthenia (moderate weakness) and $4=$ coma. Appetite was graded as $1=$ good appetite, $2=$ slightly reduced appetite $(>50 \%$ of normal food intake), $3=$ markedly reduced appetite $(<50 \%$ of normal food intake) and $4=$ complete anorexia. Vomiting was graded as no difference in frequency $=1$, not daily but more frequent than usual $=2$, vomiting once daily $=3$, and vomiting more than once a day was graded as 4 . Dehydration was graded from 1 to 4 with 1 for no dehydration and 4 indicating severe dehydration. Fur condition was graded as $1=$ normal, $2=$ some tangles, reduced grooming, $3=$ dull, tangles, infrequent grooming, and $4=$ dull and greasy fur, no grooming.

\section{Overall Therapeutic Effectiveness}

The overall therapeutic effectiveness was graded as $1=$ marked improvement, 2 = slight improvement, $3=$ unchanged to $4=$ deterioration and was assessed by the veterinarian and the owner on the last study day.

Safety data were collected throughout the study. All suspected adverse events were reported according to standard pharmacovigilance protocols. Treatment compliance was assessed by collecting and counting remaining tablets and ampoules at the end of the study.

\section{Statistical Methods}

The study was designed as a prospective, reference-controlled, nonrandomized observational study. Standard statistical methods were employed using SAS 9.3. Baseline data were compared between groups using the Wilcoxon test for interval data, MantelHaenszel test for ordinal data and Fisher's exact test for binary data.

For the comparison between treatments, changes from baseline and differences between the groups were calculated. Statistical comparisons were conducted with ANOVA, Mantel-Haenszel test and Fisher's exact test as appropriate. For all comparisons, two- 
Table 2. Demographic data at baseline (per-protocol population)

\begin{tabular}{lccc}
\hline Characteristic & $\begin{array}{l}\text { Benazepril group } \\
(n=35)\end{array}$ & $\begin{array}{l}\text { SUC group } \\
(n=33)\end{array}$ & $\begin{array}{l}p \text { value for difference } \\
\text { between groups }\end{array}$ \\
\hline Age (mean \pm SD), years & $14.1 \pm 3.1$ & $12.8 \pm 3.4$ & 0.086 \\
Weight (mean \pm SD), kg & $4.3 \pm 1$ & $4.3 \pm 1.1$ & 0.937 \\
Male sex, $n(\%)$ & $19(54)$ & $22(67)$ & 0.33 \\
Castrated, $n(\%)$ & $35(100)$ & $33(100)$ & n.a. \\
Previously diagnosed with CKD, $n(\%)$ & & & 0.82 \\
$\quad \geq 1$ year ago & $8(23)$ & $7(21)$ & \\
$\quad<1$ year ago & $17(49)$ & $14(43)$ & \\
$\quad$ No & $10(29)$ & $12(36)$ & \\
On renal diet, $n$ (\%) & $14(40)$ & $14(42)$ & 1.0 \\
Concomitant illness, $n(\%)$ & $13(37)$ & $4(12)$ & 0.025 \\
Currently under treatment for other conditions, $n(\%)$ & $11(31)$ & $4(12)$ & 0.08 \\
Blood pressure (mean \pm SD), mm Hg & $156.8 \pm 13.9$ & $156.4 \pm 15.2$ & 0.92 \\
Renal variables (means \pm SD) & & & \\
$\quad$ Serum creatinine, mg/dL & $2.52 \pm 0.56$ & $2.75 \pm 0.68$ & 0.13 \\
$\quad$ USG & $1,023.1 \pm 6.3$ & $1,020.1 \pm 6.5$ & 0.13 \\
$\quad$ UP/C & $0.28 \pm 0.2$ & $0.16 \pm 0.2$ & 0.02 \\
$\quad$ Clinical summary score & $10.7 \pm 0.9$ & $10.8 \pm 1.0$ & 0.74 \\
\hline
\end{tabular}

sided $95 \%$ confidence limits were calculated. A $p$ value $<0.05$ was considered statistically significant.

At baseline UP/C was noticeably lower in the SUC group, comparison of UP/C was performed with ANOVA adjusted for propensity scores - based on creatinine and UP/C at baseline.

The noninferiority of SUC to benazepril was assessed on the response variable change from baseline in serum creatinine. The limit for the lower boundary of the $95 \%$ confidence interval for the differences between the treatment groups at 168 days was compared to $0.6 \mathrm{mg} / \mathrm{dL}$, which was considered within the magnitude of change without clinical relevance and also represents half the difference in serum creatinine between IRIS stages 2 and 3 [12].

One aim of the study was to show noninferiority of SUC to benazepril therapy, and for this purpose, the effectiveness variables were analyzed in the per-protocol population. An additional intention-to-treat analysis was performed to evaluate the robustness of the results.

\section{Results}

\section{Study Populations}

The 12 participating practices enrolled a total of 70 cats, with 36 cats in the benazepril group and 34 cats in the SUC group (intention-to-treat population). The perprotocol population consisted of 68 cats, 35 in the benazepril cohort, and 33 in the SUC cohort. Reasons for exclusion from the study were nonfulfillment of inclusion criteria in the benazepril group $(n=1)$, and therapy with an ACEI in the SUC group $(n=1)$. Three cats with USG $=1.036$ ( 2 in the SUC group, 1 in the benazepril group) were included as a protocol deviation, because all other criteria were fulfilled. Fifty-two cats (76\%) completed the study, with 27 cats in the benazepril group and 25 cats in the SUC group. The raw data sets of the study are available in online supplemental Table 2.

In both treatment arms, 8 cats terminated the study prematurely. In the benazepril group 2 cats were euthanized because of $\mathrm{CKD}$, having increased serum creatinine and UP/C values within the study period, and 1 cat terminated the study prematurely because of worsened CKD. One cat in the SUC arm was euthanized due to worsening of $\mathrm{CKD}$, and 1 cat diagnosed with hypertension in need of hypertensive treatment was excluded from the study. All additional reasons for dropouts were not related to CKD in both treatment arms. In the benazepril group cats were excluded due to the following reasons: pancreatitis, purulent otitis, bacterial cystitis and withdrawal of owner consent, and in the SUC group cats were excluded because of an adenocarcinoma, death of unknown cause, withdrawal of owner consent and nonfulfillment of inclusion criteria.

In this observational study, cats were not randomized to either treatment arm. Comparing cats in the benazepril and the SUC group showed that age, weight, gender, clinical summary score, serum creatinine and USG were not statistically different at baseline, but both groups differed statistically when comparing UP/C (Table 2). To correct for this difference, a propensity score was used to assure comparability of both groups.

At the screening visit (per-protocol population) 22 cats in the SUC group were in IRIS stage 2 and 11 cats in IRIS stage 3 . In the benazepril group 27 cats were in stage 2 and 8 cats in stage 3 . IRIS stage and substages are displayed in Table 3 . 
Table 3. IRIS stage and substage of per-protocol population at baseline

\begin{tabular}{llcc}
\hline Iris stage & Creatinine, & SUC & $n=33$ \\
& mg/dL & $\begin{array}{l}\text { Benazepril } \\
n=35\end{array}$ \\
\hline 1 & $<1.6$ & 0 & 0 \\
2 & $1.6-2.8$ & 22 & 27 \\
3 & $2.9-5.0$ & 11 & 8 \\
4 & $>5.0$ & 0 & 0 \\
\hline IRIS substage & UP/C value & $n=33$ & $n=35$ \\
\hline 1 & $<0.2$ & 19 & 8 \\
2 & $0.2-0.4$ & 12 & 22 \\
3 & $>0.4$ & 2 & 5 \\
\hline IRIS substage & Systolic blood & $n=25$ & $n=34$ \\
& pressure, & & \\
& mm Hg & & 4 \\
1 & $<140$ & 4 & 13 \\
2 & $140-159$ & 15 & 4 \\
3 & $160-179$ & 6 & \\
4 & $\geq 180$ & 0 & \\
\hline
\end{tabular}

\section{Renal Variables}

Overall, serum creatinine remained close to baseline values during the study in both groups (Fig. 3). At the end of the study serum creatinine increased by only $0.05 \mathrm{mg} /$ $\mathrm{dL}$ in the SUC group and $0.21 \mathrm{mg} / \mathrm{dL}$ in the benazepril group (Fig. 3, $p=0.49$ ).

The change in serum creatinine to baseline did not reach statistical significance showing noninferiority of both treatment arms taking into account the noninferiority margin of $0.6 \mathrm{mg} / \mathrm{dL}$ with the upper boundary of the $95 \%$ confidence interval being $0.3 \mathrm{mg} / \mathrm{dL}$.

In the SUC group $65 \%$ of all cats had a stable or decreased serum creatinine within the study period, with up to $70 \%$ of cats with decreased serum creatinine in IRIS stage 3. Comparing both groups, there was no statistically significant difference in the number of cats progressing to a higher IRIS stage ( $p=0.78$, SUC group: 9 cats, benazepril group: 8 cats). Results were independent whether cats received renal diet or not $(n=14$ cats in both treatment arms).

\section{Clinical Summary Score}

The clinical summary score showed a rapid improvement of the cats in the SUC group within 3 days. The clinical summary score was significantly improved compared to the benazepril group on days $3(p=0.015), 7(p=0.0022)$, $28(p=0.0024), 56(p<0.0001)$ and $112(p=0.0043)$, but not on day 168 (Fig. 4). Several variables, for example general behavior, appetite score and vomiting, showed a sta- tistically significant improvement in the SUC group compared to the benazepril group at certain time points. Body weight was stable in both groups during the study period.

Overall therapeutic effectiveness scores were assessed by the owners and veterinarians. The scores for effectiveness of both treatments did not differ, with slightly better values in the SUC group not reaching significance. Veterinarians rated SUC as overall effective in $72 \%$ of cats and benazepril treatment was considered overall effective in $68 \%$ of the cats. Owners evaluated SUC as overall effective in $70 \%$ of cases and benazepril as effective in $65 \%$.

\section{Compliance}

Compliance of the owners to adhere to the study protocol was high with over $90 \%$ compliance in both treatment arms.

\section{Tolerability}

Both treatment regimens were well tolerated, 12/36 cats in the intention-to-treat population in the benazepril group (33\%), and $8 / 34$ cats in the SUC group (24\%) had $\geq 1$ adverse event reported. Five cats in each group had $\geq 1$ severe adverse event. Two cats in the benazepril group were euthanized because of the CKD, and 1 cat was euthanized due to a CKD-unrelated reason. In the SUC group 1 cat died of unknown cause, and 1 cat was euthanized because of the CKD. There were no statistically significant differences between the groups in the frequency of any of these events.

\section{Discussion}

The results of the current study showed that the multicomponent, multitarget combination SUC is noninferior to the commonly used ACEI benazepril for the treatment of cats with CKD of mild to moderate severity, with similar effects on laboratory parameters indicative of disease progression. Review of the current literature showed that most tested drugs are noninferior compared to benazepril [21-24, 42-45] (Table 4). Some of the indicated studies included a placebo group to confirm effectivity of their study drug [22, 23, 42, 45, 46]. Mizutani et al. [22] and Takenaka et al. [45] showed an increase in serum creatinine within the treatment time of 180 days in the placebo group, showing the progressive course of the disease. In the present study, a placebo group was not included due to ethical constraints and because it is widely accepted that renal function in affected cats decreases over time with increasing serum creatinine levels. The observation time of the cats in this study was in accordance with previously published data $[22-24,42,45]$ and within this time frame serum creatinine was reduced on days 28 , 56 and 112 in the SUC group (Fig. 3) but not in the bena- 


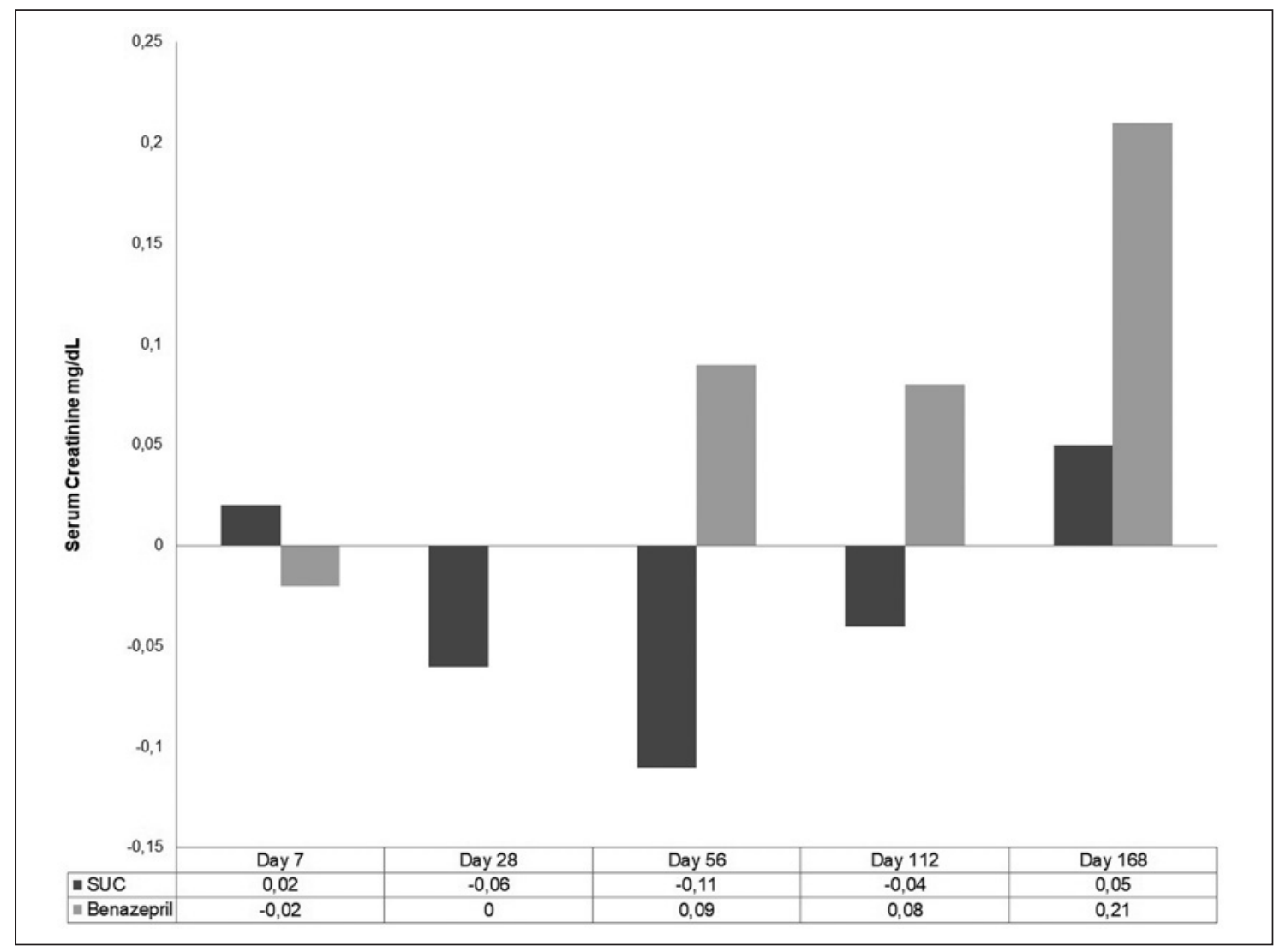

Fig. 3. Change in serum creatinine from baseline. Differences in serum creatinine between groups were not statistically significant at any time point. In the SUC group ( $\mathbf{\square})$, serum creatinine was reduced until day 112.

Fig. 4. Clinical summary score as indicator of quality of life. Mean summary score of all clinical and behavioral variables at baseline and during follow-up visits (days 3,7 , $28,56,112,168)$. The dashed line displays values of the clinical summary score of the benazepril group, and the solid line displays the values for the SUC group. Horizontal lines represent standard errors. Higher scores indicate reduced quality of life; ${ }^{*} p<0.05$ : statistically significant difference between groups.



zepril group. The quality of life, an important parameter, was assessed by King et al. [46] and Mizutani et al. [22]; in both studies, no improvement of quality of life was seen. In the present study, treatment with SUC showed a significant improvement of the quality of life on days 3 , 7, 28, 56 and 112, but not on day 168 .

Taking the results from the relevant literature together (Table 4), benazepril is still standard of care in cats with 


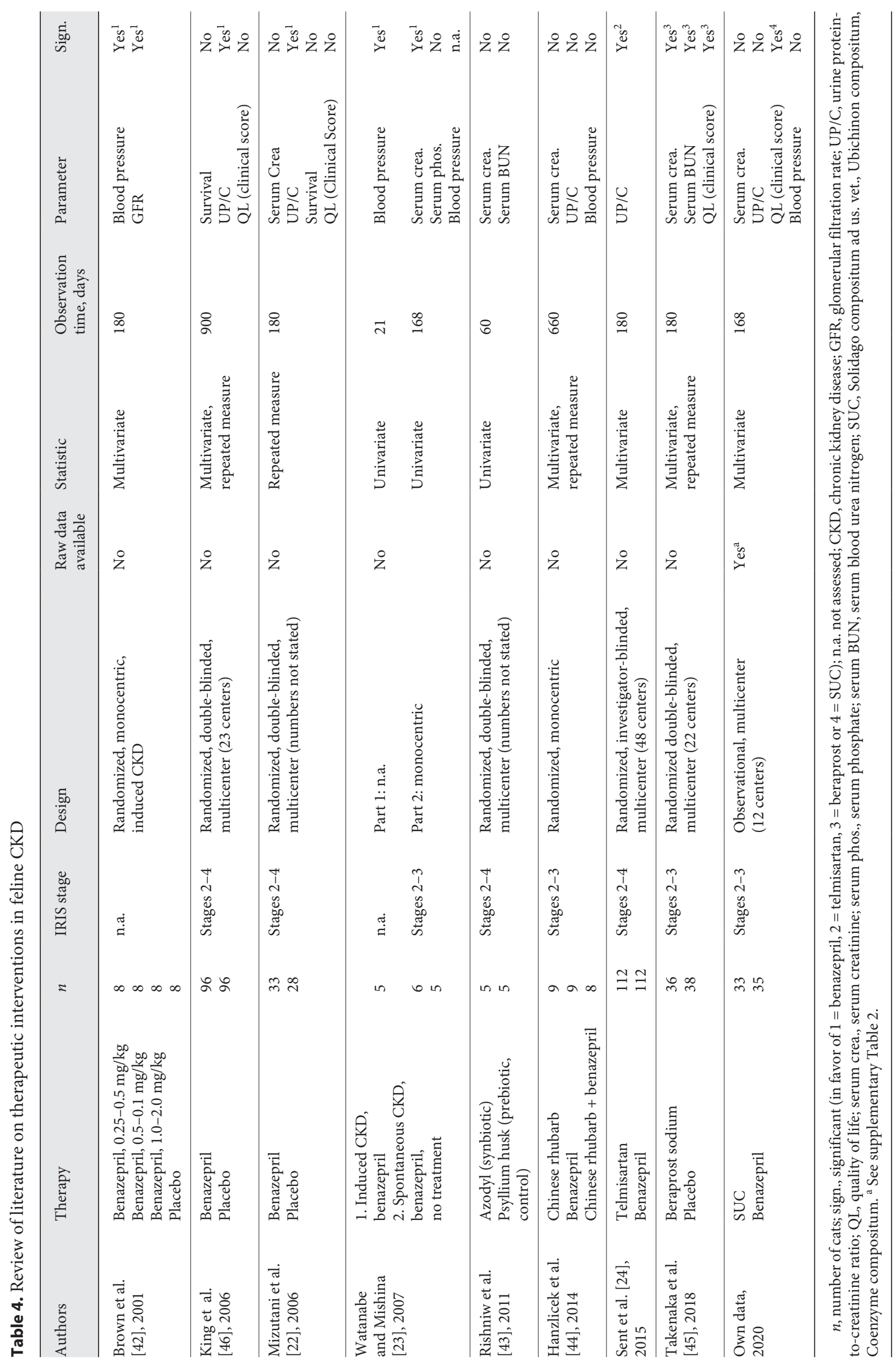


CKD, even though telmisartan has recently shown greater effects on UP/C [24].

Cats treated with SUC showed a rapid improvement of the clinical summary score presuming a better quality of life as early as day 3 after starting treatment for CKD. The difference in the clinical summary score compared to benazepril was statistically significant at all time points except on day 168. The slight reduction in the clinical summary score in the SUC group at the end of the study might have been caused by the reduced treatment frequency at this time point in the SUC group. The dose was reduced to once weekly on day 56 and this dosing regimen might not be sufficient to protect feline kidney tissue. The clinical summary score has been influenced by the fact that veterinarians and owners were not blinded to the treatment. To reduce the bias caused by unblinded design and nonrandomization, each participating study center treated all cats with either benazepril or SUC. Therefore, study centers could not compare treatment effects between groups.

In humans, ACEIs have a pivotal role in the treatment of kidney disease [47].

Benazepril is a common ACEI for the treatment of feline CKD, and studies have supported its effectiveness in the therapeutic management of cats with renal insufficiencies [21-24]. However, concerns about adverse side effects and the known negative pharmacodynamic interactions might limit the applicability. Therefore, SUC has evolved to be a complementary treatment option for feline CKD [38-40] that is well tolerated with high acceptance by owner and cat with improved quality of life.

The goal of CKD treatment is to improve quality of life in the affected cats and to slow down the progression of renal fibrosis to end-stage renal failure [16]. It was not expected to see a tremendous improvement of serum creatinine by either treatment in this study because renal fibrosis cannot be converted into normal renal tissue bringing back normal renal function. Effectiveness of CKD treatment is characterized by stabilizing or slightly improving serum creatinine values $[22,23]$. Interestingly, serum creatinine values improved during the study when SUC was given at least twice weekly (until day 55) with a stable UP/C during the study period. This effect was lost on day 112, when SUC was given only once weekly. This change in serum creatinine might indicate a dose-response relationship of SUC. On one hand, these findings might indicate that $S$. virgaurea slowed down tissue fibrosis as demonstrated in a fibroblast culture [30] to a certain extent if given at least twice weekly and that this protective effect might have been lost by underdosing SUC. On the other hand, it is possible that SUC might not have a long-term effect on the progressive course of CKD in cats. Also, for benazepril it was shown earlier that lowering the dose results in a diminished effect on the course of CKD [42].

Taking the results from the clinical summary score and serum creatinine together, it can be concluded that SUC is a new treatment option that should be given at least twice weekly. But the short follow-up time, the number of cats in the study and the dosing regimen might be the reason that the difference in the results between both treatment groups did not favor SUC. To answer these questions a larger placebo-controlled, double-blinded study with an adapted dosing regimen should be done.

The clinical summary score as measure of quality of life did not fully reflect the change in renal parameters such as serum creatinine. Serum creatinine was not significantly reduced by either treatment, but the clinical summary score showed a significant improvement of the quality of life in the SUC group. This finding was consistently seen throughout the study period suggesting an effect of the SUC treatment. This effect might partly be explained by the number of cats $(n=20)$ with improved serum creatinine in the SUC group during the study. In addition, the beneficial effect on clinical behavior was also seen in previous field studies with SUC [3840].

Observational and unblinded studies are difficult to analyze because of different population characteristics. In this study there was no statistically significant difference between groups when comparing serum creatinine. Serum creatinine is the most important prognostic indicator for severity of the disease [12]. In addition, UP/C is an important prognostic indicator, and to correct for significant differences in UP/C between both groups at baseline the propensity score was used. Comparing both groups with the propensity score no significant difference in serum creatinine at any time point was detected showing noninferiority of either treatment arm.

Eight cats in the benazepril group did not show proteinuria (UP/C <0.2) at baseline (Table 3). Nowadays, the recommended treatment would not include benazepril for these cats, but at the time the study was designed, this was the standard of care for cats with CKD [24].

SUC is designed to act on multiple different targets to protect renal tissue, therefore it can be recommended at any stage of disease independently of proteinuria to protect kidney tissue from further damage. Interestingly, even $70 \%$ of cats in IRIS stage 3 treated with SUC had a decreased serum creatinine and consequently an improved quality of life showing that SUC can be started at any time independently of IRIS stage, and treatment should be given at least twice a week in the maintenance phase to protect renal tissue from further damage. A larger study with greater statistical power would be needed to confirm these findings and to find the best dosing scheme for SUC. 


\section{Conclusions}

In summary, this observational pilot study indicates that the effectiveness of the multitarget, multicomponent therapy SUC was noninferior to that of the commonly used ACEI benazepril for the treatment of mild to moderate feline CKD over a follow-up period of 168 days. Within the limitations of the study, the results carry implications for the usefulness of SUC as an interesting new treatment option for feline CKD. There is also evidence that the dosing frequency of SUC plays a pivotal role in protecting kidney tissue to stabilize this fatal disease in cats. Further studies, including possible use as add-on therapy and comparisons with newer treatment options seem appropriate.

\section{Acknowledgement}

We want to thank all contributing veterinarians for dedicating their time for the study.

\section{Statement of Ethics}

All owners gave their informed consent for their cats to be included in the study. The design and conduct of the study were in accordance with the guidelines for GCP VICH GL9 [20].

\section{Disclosure Statement}

U.B. has no competing interest to declare. G.B. is an employee of CRO Klifovet AG, who received consultancy fees from Heel $\mathrm{GmbH}$. P.K. has received consultancy fees from Heel GmbH. E.R. is an employee of Heel $\mathrm{GmbH}$.

\section{Funding Sources}

This work was supported by a research grant from Heel GmbH.

\section{Author Contributions}

U.B. analyzed and interpreted the data. G.B. designed the study and analyzed the data. P.K. interpreted the data and was instrumental in preparing the manuscript. E.R. designed the study, interpreted the data and contributed to the writing of the manuscript. All authors read and approved the final paper.

\section{References}

1 Bartges JW. Chronic kidney disease in dogs and cats [vi.]. Vet Clin North Am Small Anim Pract. 2012 Jul;42(4):669-92.

2 Brown CA, Elliott J, Schmiedt CW, Brown SA. Chronic Kidney Disease in Aged Cats: Clinical Features, Morphology, and Proposed Pathogeneses. Vet Pathol. 2016 Mar;53(2): 309-26.

3 Marino CL, Lascelles BD, Vaden SL, Gruen ME, Marks SL. Prevalence and classification of chronic kidney disease in cats randomly selected from four age groups and in cats recruited for degenerative joint disease studies. J Feline Med Surg. 2014 Jun;16(6):465-72.

4 Greene JP, Lefebvre SL, Wang M, Yang M, Lund EM, Polzin DJ. Risk factors associated with the development of chronic kidney disease in cats evaluated at primary care veterinary hospitals. J Am Vet Med Assoc. 2014 Feb;244(3):320-7.

5 Hamilton JB, Hamilton RS, Mestler GE. Duration of life and causes of death in domestic cats: influence of sex, gonadectomy, and inbreeding. J Gerontol. 1969 Oct;24(4):427-37.

6 Lund EM, Armstrong PJ, Kirk CA, Kolar LM, Klausner JS. Health status and population characteristics of dogs and cats examined at private veterinary practices in the United States. J Am Vet Med Assoc. 1999 May; 214(9):1336-41.

7 Egenvall A, Nødtvedt A, Häggström J, Ström Holst B, Möller L, Bonnett BN. Mortality of life-insured Swedish cats during 1999-2006: age, breed, sex, and diagnosis. J Vet Intern Med. 2009 Nov-Dec;23(6):1175-83.

8 O’Neill DG, Church DB, McGreevy PD, Thomson PC, Brodbelt DC. Longevity and mortality of cats attending primary care veterinary practices in England. J Feline Med Surg. 2015 Feb;17(2):125-33.

9 Freeman LM, Lachaud MP, Matthews S, Rhodes L, Zollers B. Evaluation of Weight Loss Over Time in Cats with Chronic Kidney Disease. J Vet Intern Med. 2016 Sep;30(5): 1661-6.

10 Sparkes AH, Caney S, Chalhoub S, Elliott J, Finch N, Gajanayake I, et al. ISFM Consensus Guidelines on the Diagnosis and Management of Feline Chronic Kidney Disease. J Feline Med Surg. 2016 Mar;18(3):219-39.

11 Vogt AH, Rodan I, Brown M, Brown S, Buffington CA, Forman MJ, et al.; European Society of Feline Medicine; Feline Advisory Bureaus WellCat for Life. AAFP-AAHA: feline life stage guidelines. J Am Anim Hosp Assoc. 2010 Jan-Feb;46(1):70-85.

12 IRIS Staging of CKD in cats, http://iris-kidney.com/pdf/003-5559.001-iris-websitestaging-of-ckd-pdf_220116-final.pdf\#page=7

13 King JN, Tasker S, Gunn-Moore DA, Strehlau G; BENRIC (benazepril in renal insufficiency in cats) Study Group. Prognostic factors in cats with chronic kidney disease. J Vet Intern Med. 2007 Sep-Oct;21(5):906-16.

14 Finch NC, Syme HM, Elliott J. Repeated measurements of renal function in evaluating its decline in cats. J Feline Med Surg. 2018 Dec; 20(12):1144-8.

15 Jepson RE. Current Understanding of the Pathogenesis of Progressive Chronic Kidney Disease in Cats. Vet Clin North Am Small Anim Pract. 2016 Nov;46(6):1015-48.

16 Taylor SS, Sparkes AH, Briscoe K, Carter J, Sala SC, Jepson RE, et al. ISFM consensus guidelines on the diagnosis and management of hypertension in cats. J Feline Med Surg. 2017 Mar;19(3):288-303.

17 Roudebush P, Polzin DJ, Ross SJ, Towell TL, Adams LG, Dru Forrester S. Therapies for feline chronic kidney disease. What is the evidence? J Feline Med Surg. 2009 Mar;11(3): 195-210.

18 Polzin DJ, Churchill JA. Controversies in Veterinary Nephrology: Renal Diets Are Indicated for Cats with International Renal Interest Society Chronic Kidney Disease Stages 2 to 4: The Pro View. Vet Clin North Am Small Anim Pract. 2016 Nov;46(6):1049-65.

19 Vaden SL, Elliott J. Management of Proteinuria in Dogs and Cats with Chronic Kidney Disease. Vet Clin North Am Small Anim Pract. 2016 Nov;46(6):1115-30.

20 Caney SM. An online survey of dietary and phosphate binder practices of owners of cats with chronic kidney disease. J Feline Med Surg. 2017 Oct;19(10):1040-7.

21 King JN, Seewald W, King S, Goldenthal E. Benazepril increases feed intake and body weight in healthy growing cats. J Vet Pharmacol Ther. 2006 Jun;29(3):225-7.

22 Mizutani H, Koyama H, Watanabe T, Kitagawa H, Nakano M, Kajiwara K, et al. Evaluation of the clinical efficacy of benazepril in the treatment of chronic renal insufficiency in cats. J Vet Intern Med. 2006 Sep-Oct;20(5): 1074-9.

23 Watanabe T, Mishina M. Effects of benazepril hydrochloride in cats with experimentally induced or spontaneously occurring chronic renal failure. J Vet Med Sci. 2007 Oct;69(10): 1015-23. 
24 Sent U, Gössl R, Elliott J, Syme HM, Zimmering T. Comparison of Efficacy of Long-term Oral Treatment with Telmisartan and Benaz epril in Cats with Chronic Kidney Disease. J Vet Intern Med. 2015 Nov-Dec;29(6):1479_ 87.

25 Chakrabarti S, Syme HM, Brown CA, Elliott J. Histomorphometry of feline chronic kidney disease and correlation with markers of renal dysfunction. Vet Pathol. 2013 Jan;50(1):14755.

26 McLeland SM, Cianciolo RE, Duncan CG Quimby JM. A comparison of biochemical and histopathologic staging in cats with chronic kidney disease. Vet Pathol. 2015 May; 52(3):524-34

27 Dickerson VM, Rissi DR, Brown CA, Brown SA, Schmiedt CW. Assessment of Acute Kidney Injury and Renal Fibrosis after Renal Ischemia Protocols in Cats. Comp Med. 2017 Feb;67(1):56-66.

28 Melk A, Schmidt BM, Vongwiwatana A, Rayner DC, Halloran PF. Increased expression of senescence-associated cell cycle inhibitor p16INK4a in deteriorating renal transplants and diseased native kidney. Am Transplant. 2005 Jun;5(6):1375-82.

29 Lawson JS, Liu HH, Syme HM, Purcell R, Wheeler-Jones CP, Elliott J. The cat as a naturally occurring model of renal interstitial fibrosis: characterisation of primary feline proximal tubular epithelial cells and comparative pro-fibrotic effects of TGF- $\beta 1$. PLoS One. 2018 Aug;13(8):e0202577.

30 Lämmermann I, Terlecki-Zaniewicz L, Weinmüllner R, Schosserer M, Dellago H, de Matos Branco $\mathrm{AD}$, et al. Blocking negative effects of senescence in human skin fibroblasts with a plant extract. NPJ Aging Mech Dis. 2018 Apr; 4(1):4.
31 Melzig MF. [Goldenrod-a classical exponent in the urological phytotherapy]. Wien Med Wochenschr. 2004 Nov; 154(21-22): 523-7.

32 Lefebvre HP, Brown SA, Chetboul V, King JN, Pouchelon JL, Toutain PL. Angiotensinconverting enzyme inhibitors in veterinary medicine. Curr Pharm Des. 2007;13(13): 1347-61

33 Aziz DM, Schnurrbusch U, Enbergs H. Effects of two homeopathic complexes on bovine sperm mitochondrial activity. Homeopathy. 2012 Apr;101(2):99-102.

34 Girin S, Savinova I, Antonenko I, Naumenko $\mathrm{N}$. The effect of ultra low concentrations of some biologically active substances on the aerobic respiration. Cellbio (Irvine Calif). 2016;5(1):1-13.

35 Granata S, Zaza G, Simone S, Villani G, Latorre D, Pontrelli P, et al. Mitochondrial dysregulation and oxidative stress in patients with chronic kidney disease. BMC Genomics. 2009 Aug;10(1):388.

36 Okamura DM, Pennathur S. The balance of powers: redox regulation of fibrogenic pathways in kidney injury. Redox Biol. 2015 Dec; 6:495-504.

37 Zsengellér ZK, Rosen S. The Use of Cytochrome C Oxidase Enzyme Activity and Immunohistochemistry in Defining Mitochondrial Injury in Kidney Disease. J Histochem Cytochem. 2016 Sep;64(9):546-55.

38 Ulrich U. Behandlungsmöglichkeiten der chronischen Niereninsuffizienz der Katze mit biologischen Arzneimitteln. Kleintiermedizin. 2004;7:135-9.

39 Eichentopf A, Eichentopf F. Ergebnisse zur chronischen Niereninsuffizienz der Katze bei biologischer Behandlung. Biol Tiermed. 2006; 33:31-4.

40 Grelck G. Neue Anwendungsbeobachtung belegt Wirksamkeit und Verträglichkeit von SUC bei Katzen mit chronischer Nierenerkrankung (CNE). Kleintierkonkret. 2015; 17(6):42-4.
41 Good Clinical Practice VICH GL9. VICH International Co-operation on Harmonisation of Technical Requirements for Registration of Veterinary Medicinal Products. http://www. vichsec.org/component/attachments/attachments $/ 142 . h t m l$ ?task=download

42 Brown SA, Brown CA, Jacobs G, Stiles J, Hendi RS, Wilson S. Effects of the angiotensin converting enzyme inhibitor benazepril in cats with induced renal insufficiency. Am J Vet Res. 2001 Mar;62(3):375-83.

43 Rishniw M, Wynn SG. Azodyl, a synbiotic, fails to alter azotemia in cats with chronic kidney disease when sprinkled onto food. J Feline Med Surg. 2011 Jun;13(6):405-9.

44 Hanzlicek AS, Roof CJ, Sanderson MW, Grauer GF. The Effect of Chinese rhubarb, Rheum officinale, with and without benazepril on the progression of naturally occurring chronic kidney disease in cats. J Vet Intern Med. 2014 Jul-Aug;28(4):1221-8.

45 Takenaka M, Iio A, Sato R, Sakamoto T, Kurumatani H; KT-140 Clinical Study Group. A Double-blind, Placebo-controlled, Multicenter, Prospective, Randomized Study of Beraprost Sodium Treatment for Cats with Chronic Kidney Disease. J Vet Intern Med. 2018 Jan;32(1):236-48.

46 King JN, Gunn-Moore DA, Tasker S, Gleadhill A, Strehlau G; Benazepril in Renal Insufficiency in Cats Study Group. Tolerability and efficacy of benazepril in cats with chronic kidney disease. J Vet Intern Med. 2006 Sep-Oct; 20(5):1054-64.

47 Aldigier JC, Meur YL, Brunel P. Protection of Renal Function with ACE Inhibitors: experience with Benazepril. Clin Drug Investig. 1998;16(6):463-72. 